\title{
COMPETENT ALTERNATIVE MODEL FOR THE PEASANTS' MEDICAL EXPENDITURES IN CHINA: A CASE OF NEW RURAL COOPERATIVE MEDICAL SERVICE SYSTEM (NRCMS) IN ZHEJIANG PROVINCE
}

\author{
Lu Wencong, Cheng Ying, Mohummed Shofi Ullah Mazumder*
}

\begin{abstract}
:
The New Rural Cooperative Medical Service System (NRCMS) in China has been established to ensure improved medical care support for all categories of Chinese peasants to offset their burden of excessive medical care expenditures. The primary aim of this paper is to identify an appropriate alternative modelling approach for the patients' medical expenditures. Data were collected from Jiaojiang city through cluster and multistage random sampling procedure, which was comprised of 4,630 enrolled rural people under NRCMS. The paper presented the first comparison of common econometric medical expenditures modelling approaches. Major findings reveal that the Generalized Linear Model (GLM) predictive accuracy appears to be better than the Finite Mixture Model (FMM) and GLM (log link) was the best performer among all approaches. It may be attributed due to the structural difference of medical expenditures between China and other developing countries compared to the developed countries. This suggests that the Chinese government may find an alternative to choose GLM approach among others to minimize the peasants' medical expenditures under NRCMS.
\end{abstract}

Keywords: New Rural Cooperative Medical Service System (NRCMS), Patients' Medical Expenditures, Generalized Linear Model (GLM) and Finite Mixture Model (FMM).

JEL Classification: C52, H51, I18

\section{Introduction}

China has undergone a period of rapid economic development and industrialization since the 1980s. This was paralleled by noticeable change in the rural area and reform in agriculture. The peasants' income has increased, but medical expenditures have been rising at a pace that is above the average growth rate of the peasants' income. According to the 3rd National Health Service Investigation, $31.4 \%$ of the Chinese peasants took

* Lu Wencong, Dept. of Agriculture, Economics and Management, School of Management, Zhejiang University, Hangzhou-310085, China (wenclu@zju.edu.cn); Cheng Ying (corresponding author), School of Management, Zhejiang University, Hangzhou, China \& Accounting College, Hangzhou Dianzi University, Hangzhou, China (chengying_hz@163.com); Mohummed Shofi Ullah Mazumder, School of Management, Zhejiang University, Hangzhou, China \& Dept. of AEIS, Sher-e-Bangla Agril. University, Sher-e-Bangla Nagar, Dhaka-1207, Bangladesh (shofi_keron@yahoo.com).

The paper was supported by Scientific Research Project of The Education Department of Zhejiang Province of China (Project No. Y201432093) and the National Science Foundation of China (Project No. 71073139). 
self-care once becoming sick. Forty to $60 \%$ and even more of the peasants live in poor state of health either due to the illness/injury or lack of proper medicare.

In order to relieve the striking contradictions between the limited payment capacity of the peasants and the rising medical expenditures in the rural area, the Chinese government established the New Rural Cooperative Medical Service System (NRCMS) in October 2002. Despite great differences in industrialized level, peasants' income and the demand for medical service among the districts (countries) in China, the macrocosmic policies of NRCMS, which contain the coinsurance rates and the co-payment are different among the countries under the same macro principles. All the financing of NRCMS in each country is the mixture of public and private sources. The public source consists of the funds allocated by the central, the provincial, the municipal and the district governments. The private source is used for premiums collection purposes locally. Both the funds from the public and private sources are also different in the amount among the countries. An entire family unit must enrol to avoid the adverse selection for these services. At the end of 2011, about 832 million peasants had voluntarily enrolled into the NRCMS (Table1). The key objective of NRCMS is to achieve whole coverage of all rural residents.

The Chinese government followed a policy of low benefits, low contributions and high co-payments, but both the NRCMS funds spending and the number of beneficiaries kept increasing rapidly as the enrolled rates is increasing. Furthermore, the growth rate of spending was distinctly above the growth rate of amount of beneficiaries. This shows that the excepted NRCMS funds spending per capita increased when the frequency of the use of medical service increased. The increases were due to the rise of medical services' price and the NRCMS reducing financial barriers to access medical services. In the long term, the growth rate of the NRCMS funds spending will not slow down for the changing tendency of the influencing factors and the growth in the spending will be higher because of the increments of base.

Table 1

The New Rural Cooperative Medical Service System in China, 2004-2011

\begin{tabular}{|c|c|c|c|c|c|c|}
\hline \multirow{2}{*}{ Year } & \multirow{2}{*}{$\begin{array}{c}\text { Enrolled } \\
\text { peasants } \\
\text { (million) }\end{array}$} & \multirow{2}{*}{$\begin{array}{c}\text { Enrolment } \\
\text { Rate* }\end{array}$} & \multicolumn{2}{|c|}{ Used Funds } & \multicolumn{2}{c|}{ Beneficiaries } \\
\cline { 4 - 7 } & & $\begin{array}{c}\text { Total } \\
\text { (million yuan**) }\end{array}$ & $\begin{array}{c}\text { Year/Year } \\
(\%)\end{array}$ & $\begin{array}{c}\text { Total } \\
\text { (million) }\end{array}$ & $\begin{array}{c}\text { Year/Year } \\
(\%)\end{array}$ \\
\hline 2004 & 80 & 75.20 & 2637 & - & 76 & - \\
\hline 2005 & 179 & 75.66 & 6175 & 134.17 & 122 & 60.53 \\
\hline 2006 & 410 & 80.66 & 15581 & 152.32 & 272 & 122.95 \\
\hline 2007 & 726 & 86.20 & 34663 & 122.47 & 453 & 66.54 \\
\hline 2008 & 815 & 91.53 & 66231 & 91.07 & 585 & 29.14 \\
\hline 2009 & 833 & 94.00 & 92290 & 39.35 & 759 & 29.74 \\
\hline 2010 & 836 & 96.00 & 118780 & 28.70 & 1087 & 43.21 \\
\hline 2011 & 832 & 97.50 & 171020 & 43.98 & 1315 & 20.98 \\
\hline 2012 & 805 & 98.00 & - & - & 1745 & 32.70 \\
\hline
\end{tabular}

Source: National Statistical Communiqué on the Development of Health Service, 2004-2012.

* 1 Yuan=US\$0.146, **Enrolment rate: the percentage of the enrolled peasants in total Chinese peasants 
As the spending of NRCMS funds has been growing rapidly, the issue of financial sustainability is of great importance. Though the financing is the mix of public and private sources, the funds allocated by the public at various levels have been the largest financier, accounting for more than $80 \%$ since 2008. At the same time, once NRCMS has serious financial sustainability problems, the government may undertake the ultimate responsibility to cover the shortfall between expenditures and revenue. To predict the peasants' medical expenditures under NRCMS may serve as a parameter, which may help the government formulate an appropriate policy and determine the amount of the relevant financial allocation. As there are several modelling approaches, which are used to predict accurately individual's medical expenditures, a test of common econometric models and identification of the most effective one for the patients' medical expenditures under NRCMS could be beneficial for to the government.

\section{Econometric Approaches}

The demand of both medical care and health insurance are derived from demand of health sector. Two theoretical and econometric frameworks are popularly used in the literature to analyse the individual demand and decision-making regarding health including medical care and health insurance. These are both static and dynamic analyses. Through static analysis, health showed as one of the products chosen by individual based on the classical utility theory and to analyse the determinate of health demand (Becker, 1964), while in case of dynamic analysis, health showed as health capital stock depreciated by age. Thus the medical care demand would grow for replenishing the health capital stock when the stock depreciated rate (age) increases (Grossman, 1972).

The medical expenditures vary from person to person for the difference of individual characteristics, such as severity of illness, socio-economic conditions, probability of taking support service from any hospital, medicine using tendency and the patterns of medical care support seeking behaviour. The importance of health insurance in medical care demand is also one of the burning issues. The RAND Health Insurance Experiment was the most scientifically rigorous study about the demand for medical care under different health insurance coverage in the United States. The study showed that the distribution of annual medical expenditure by person had three dimensions. Firstly, about $20 \%$ of the people did not have any medical expenditure in any given year, secondly, the remaining $80 \%$ of the people had positive expenditures, which were distributed approximately in log-normal form and highly skewed to the right and thirdly, the right tail of the distribution is longer than the log-normal distribution since $10 \%$ of people had high medical expenditures for admission into hospital (Duan, 1983). In recent years, the same studies with little modification were further conducted and showed that the medical expenditures in the developed countries usually exhibit the distribution with a long, thick right tale and a substantial mass at zero. In other words, it has been observed that the majority of the population did not have any 
medical expenditure, the small proportion had high expenditures (secondary care), and the even smaller, but non-negligible proportion had extremely high expenditures (tertiary care) (Deb \& Trivedi, 2002; Sosa-Rubi, 2004; Rein, 2005). But Rajkotia (2009) showed significant contrary findings from developed countries and he found that the distribution of medical expenditures in Ghana exhibited a long, thin right tale and a substantial mass at zero.

The two-part model (TPM) is a widely-used approach to predict the medical expenditures that are favoured by health economists (Duan, 1983; Hay \& Olsen, 1984; Blough et al., 1999). The individual's behaviour is separated into two stages: a decision for using medical care and a decision for the level of medical expenditures. As the separation, the general form of the TPM is as follows:

$$
E\left(\mathrm{y}_{i} \mid x_{i}\right)=\operatorname{pr}\left(y_{i}>0 \mid x_{i}\right) E\left(\mathrm{y}_{i} \mid x_{i}, y_{i}>0\right)
$$

The first part $\operatorname{pr}\left(y_{i}>0 \mid x_{i}\right)$ predicts the probability of having any medical expenditure, and the second part $E\left(y_{i} \mid x_{i}, y_{i}>0\right)$ predicts medical expenditures conditional on being greater than zero. The unconditional expected medical expenditures for an individual are obtained by multiplying the predicted outcome from the two parts of the model. The TPM's structure is also found consistent with the principle-agent framework (Kenkel, 1990). The decision for medical support is a major individual decision and it is related to personal characteristics (the principle). The intensity of medical support mainly depends on medical system's properties and physician preferences (the agent). Theoretically, the model more closely fits the distribution of medical expenditures and also may provide more accurate estimation. It may contribute to the distribution in TPM since it seems to be closer to the normality by correcting the problem with lots of non-spenders and heavy skewness. Empirically, the first part of TPM is typically a probit or logit regression, but many approaches used for the second part in the econometric literature. Among all approaches, most often there are the following three favourite, but dispute approaches used for the second part of TPM.

\subsection{Ordinary Least Squares (OLS)}

There are two forms of OLS: linear form and log form. The linear form of OLS is as follows:

$$
Y_{i}=x_{i} \beta_{1}+\varepsilon_{i}
$$

Where $x_{i}$ is a row vector of explanatory variables and $\beta_{1}$ is a column vector of estimated coefficients. It is ordinary least squares (OLS) of $\beta_{1}$ is $\widehat{\beta}_{1}=\left(X^{\prime} X\right)^{-1} X^{\prime} Y$. It is the simplest form without any adjustments to the non-normal distribution of the medical expenditures, so it yields unbiased estimates - if the model is linear $(E(Y)=X \beta)$ and $\varepsilon$ is independent of $x_{i}$ - but inaccurate forecasts. But the limitation is, if the error is not normally distributed, the predictive accuracy will be sensitive to extreme values. 
The log form of OLS (LOLS) takes a Box-Cox log-transformation of medical expenditures and then analyse the linear model on the log scale. The non-normal distributed expenditures data after transforming into the log-scale, it becomes bell-shaped normal distribution and then OLS regression was used to estimate the linear model. It is due to the zero outcomes are ignored conditioned for the probability of any medical use is positive. The general form of LOLS is as follows:

$$
\ln \left(y_{i}\right)=x_{i} \beta_{2}+\varepsilon_{2 i} .
$$

$\varepsilon$ needs not to be independent and identically distributed (i.i.d) when $E(\varepsilon)=0$ and $E\left(x^{\prime} \varepsilon=0\right)$. If $\varepsilon \sim N\left(0, \sigma_{\varepsilon}^{2}\right), E(y \mid x)=\exp \left(x \beta+0.5 \sigma_{\varepsilon}^{2}\right)$. If $\varepsilon$ is not normally distributed, but is i.i.d. or both the mean and variance of $\exp (\varepsilon)$ are constant, $E(y \mid x)=E(\exp (\varepsilon)) * \exp (x \beta)$. If $\varepsilon$ is heteroskedasticity in $\mathrm{x}$, $\ln (E(y \mid x))=x \beta+\ln (f(x))$ and $\ln (E(y \mid x))=x \beta+0.5 \sigma_{\varepsilon}^{2}(x)$ After that, re-transform the outcome of $\mathrm{y}$ on the log-scale into the original scale to arrive at a logical conclusion by a smearing estimator (SE). SE $=\exp \left(X_{0} \hat{\beta}\right) * n^{-1} \sum \exp \left(\hat{\varepsilon}_{i}\right)$, where $\hat{\varepsilon}$ denotes the least squares residual. While the normal assumption holds and the error distribution does not depend on the characteristics, the smearing estimator is statistically more consistent than the linear form of OLS. While retransformation into the original scale even using SE, the heteroskedasticity still makes the estimation biased but inefficient for the heavy skewness of the distribution of expenditures (Buntin \& Zaslavsky, 2004).

\section{Generalized Linear Model (GLM)}

The GLM approach is also used to address the problem of transforming log outcomes since the LOLS approach may not be optimal for the medical expenditures' analyses. Instead of parametrically transforming the data, GLM directly chooses a link function $g\left(\mu_{i}\right)=x_{i} \beta$ between the observed raw-scale y $(\mu=E(y \mid x))$ and the linear predictor of the model $(x \beta)$ (McCullagh \& Nelder, 1989). The form of link functions includes the log, power, identity, probit, and so on. And y is assumed to be generated from a distribution in the exponential family with probability density function which includes the gamma, normal, binomial, poison distributions and so on. The gamma distribution with a log link and power link were found to fit claims data well, which are most commonly used to predict the medical expenditures in the actuarial and econometric literature. But it is still in controversy, for which is the optimal (Klugman. et al., 2008) gamma distribution: $g(\mu)=\mu^{-1}$

$$
\begin{aligned}
& \text { log link: } g(\mu)=\ln (\mu)=x_{i} \beta_{3}, \\
& \text { power link: } g(\lambda, \mu)=\left\{\begin{array}{l}
\mu^{\lambda}, \lambda \neq 0 \\
\log (\mu), \lambda=0
\end{array}\right.
\end{aligned}
$$

GLM, in fact, addresses the problems of retransformation inherent in the LLOS approach to the non-normal distribution of the medical expenditures by the use of a link 
function and the maximum likelihood estimation. The effects of the covariates known as age, gender and others on medical expenditures are assumed to be same in GLM. But some literature demonstrated that there is unobserved population heterogeneity that is opposite to GLM's assumption. (Gerdtham \& Trivedi 2000; Sosa-Rubi, 2004).

\subsection{Finite Mixture Model (FMM)}

FMM assumes that an individual's demand for medical care is based on individual's latent attitude to the medical services, but it cannot be observed in the claims data. In other words, it seems like unobserved population heterogeneity. So the population is regarded as an additive mixture of unobserved sub-population from $\mathrm{S}$ distinct in proportions $\pi_{j}(j=1, \ldots, S)$, which may provide a natural and intuitively attractive representation of heterogeneity, where $\pi_{j}>0, \sum_{j=1}^{S} \pi_{j}=1$ and the labelling restriction $\pi_{1} \geq \pi_{2} \geq \cdots \geq \pi_{S}$ that may satisfy by rearrangement. The finite mixture density for observation $i, i=1, \ldots, n$, may illustrate by following formula:

$$
f\left(y_{i} \mid \theta\right)=\sum_{j=1}^{S} \pi_{j} f_{j}\left(y_{i} \mid \theta_{j}\right), i=1, \ldots, n,
$$

Where, the sum of the right-hand side term is produced by the mixing probability $\pi_{j}$ and the sub-population density $f_{j}\left(y_{i} \mid \theta_{j}\right)$. FMM assumes that the data are drawn from those sub-populations whose parameters can be estimated. The probability of individual membership in each sub-population can be estimated. The component distributions being the negative binomial densities may be illustrated by following formula:

$$
f_{j}\left(y_{i} \mid \theta_{j}\right)=\frac{\Psi\left(y_{i}+\gamma_{j, i}\right)}{\Psi\left(\gamma_{j, i}\right) \Psi\left(y_{i}+1\right)}\left(\frac{\gamma_{j, i}}{\lambda_{j, i}+\gamma_{j, i}}\right)^{\gamma_{j, i}}\left(\frac{\lambda_{j, i}}{\lambda_{j, i}+\gamma_{j, i}}\right)^{y_{i}}
$$

where $\Psi(\bullet)$ is gamma function $j=1, \ldots, S, \lambda_{j, i}=\exp \left(x_{i}^{\prime} \beta_{j}\right), \gamma_{j, i}=\left(1 / a_{j}\right) \lambda_{j, i}^{k}$. $\left(\beta_{j}, \alpha_{j}\right)$ is unrestrained among the sub-populations. $E\left(y_{i} \mid x_{i}\right)=\bar{\lambda}_{i}=\sum_{j=1}^{S} \pi_{j \lambda_{j i}}$, $\operatorname{Var}\left(y_{i} \mid x_{i}\right)=\sum_{j=1} \pi_{j} \lambda_{j i}^{2}\left(1+\alpha_{j} \lambda_{j i}^{-k}\right)+\bar{\lambda}_{i}-\bar{\lambda}_{i}^{2}$. This density is general and flexible, and would accommodate patterns of over dispersion expected in the claims data.

The mathematical estimation of the number of latent sub-populations (S) is very complicated in absence of strong theory. Two or three sub-samples are commonly used to predict the individual's medical expenditures. Though the FMM approach showed better performance among all other modelling approaches by stratifying beneficiaries in a number of studies that were conducted in industrialized countries (Deb \& Trivedi, 2002; Rein, 2005), but some studies conducted in developing countries found contrary results. Rajkotia (2009) found that FMM could not offer better predictive accuracy 
than other approaches and performed even worse in many cases by using claims data from the National Health Insurance System (NHIS) in Ghana. This suggests that the structure of medical care in developing countries is fundamentally different from those of developed countries. So the econometric development of modelling approaches in developed countries may not apply to the developing countries such as in China.

However, yet in China, There is no or very little research conducted rigorously against the comparison and the choice of the modelling approaches using NRCMS claims data. The majority of the research conducted their studies pertaining to the medical expenditures who used the very simple linear model (Analysis of Covariance, ANOCOVA) (Zhao, 2006; Xie, 2009). Though some researchers used TPM (Mocan, 2004; Feng, 2006; Lin \& Shu, 2007; Huang \& Gan, 2010), but they only used the linear form or log form of OLS in the second part of TPM without considering the modelling approaches difference and also did not analyse whether GLM or FMM is applicable to China including other developing countries.

\section{Methodology of the Study}

\subsection{Source of data, sampling and research design}

As a part of Chinese social insurance, the rural people enrol to New Rural Cooperative Medical Service System (NRCMS) and receive medical care at a price discount in some cases. The NRCMS permits different policy for different provinces and it is difficult to collect information from different provincial NRCMS authority. Due to these reasons the researchers considered symbolic data from one province for maintaining accuracy to identify the most competent alternative modelling approach for the patients' medical expenditures. Data were collected through cluster and multistage random sampling, a resident group of 4,630 enrolled rural people in 11 towns purposely from Jiaojiang city under Zhejiang province. These towns were considered representative from three different points of view. Three towns such as Baiyun, Haimen and Jiazhi were selected as urbanized spot of the central district of Jiaojiang city. Hongjia, Sanjia and Xiachen are another three towns selected as the relatively economically developed spot and the rest five towns, namely Dachen, Nongchang, Yuye, Qiansuo and Zhangan were selected as less urbanized and less industrialized.

The resident group of 4,630 enrolled rural people was treated as research sample to compare predictive accuracy and find out the competent one regarding whole medical expenditures among all of the approaches. Within this sample, 1492 patients have enjoyed medical service support under NRCMS in the study period (2011).

Moreover, under NRCMS, the concerned authority stored only little basic demographic information of the enrolled respondents, such as their age, gender, family size and the region. But the medical expenditures would be influenced by health conditions of each individual. So the study chooses to use age, gender, family size and the region as explanatory variables $x_{i}$ in Model 1 and add Quality of Well-being Scale (QWB) 
as a new explanatory variable in Model 2. The QWB was designed and developed by Kaplan and Anderson (1988). It is an objective indicator based on the health conditions of individual and also a subjective indicator based on the self-assessment of the health conditions by the individual. It combines preference-weighted measures of symptoms and function to provide a numerical point-in-time expression of well-being, ranging from 0 for death to 1.0 for asymptomatic optimum function generated by the underlying disease or injury under different treatment variables. The same approach as Kaplan's is used to integrate the QWB in this study to display the health conditions of individual in 2011. The calculating formulae (function scales, with step definitions and calculating weights) used are described in Appendix I. Dependent variable $y_{i}$ both denotes the peasant's total medical expenditures in 2011 in Model 1 and Model 2. It includes outpatient, inpatient, emergency department and pharmacy costs. The variables specification and the descriptive statistics appear in Table 2.

Table 2

\section{Specification and Summary Statistics of the Variables}

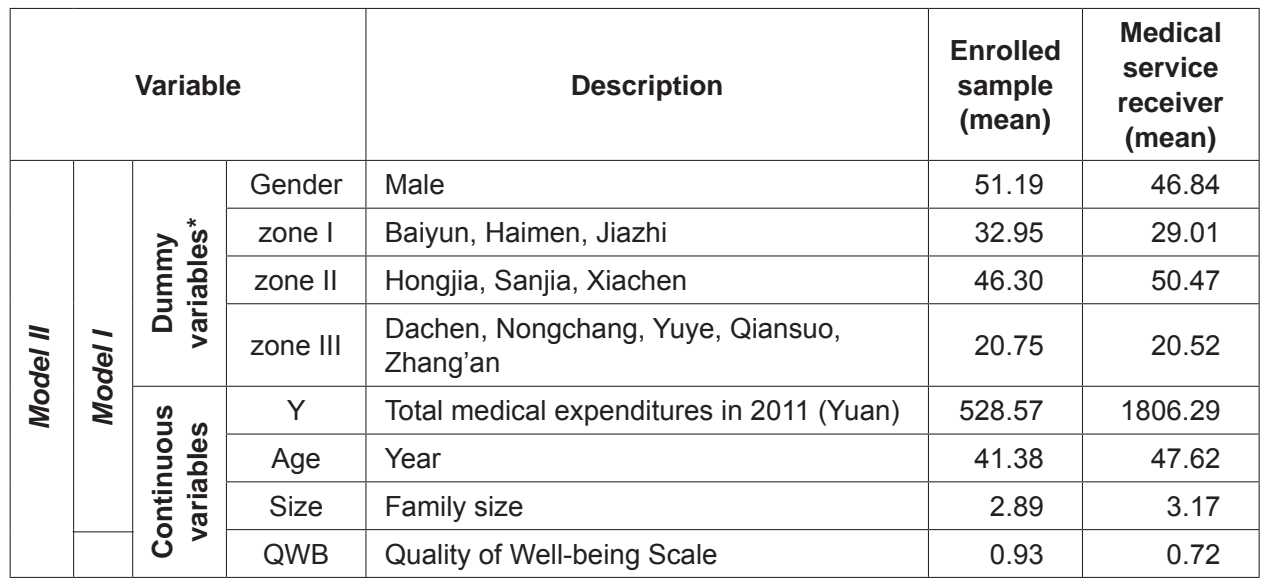

*0=no, $1=y e s$, percents of the value" $1 ", \%$

\subsection{Modelling}

The researcher chooses TPM as the form of both Model I and Model II based on distribution of medical care expenditures characteristics through NRCMS. The probit regression was used in the part one of TPM and the form of this part is as follows:

$$
f\left(\eta_{i} \mid \theta\right)=\frac{\Gamma\left(\eta_{i}+\gamma_{i}\right)}{\Gamma\left(\gamma_{i}\right) \Gamma\left(\eta_{i}+1\right)}\left(\frac{\gamma_{i}}{\lambda_{i}+\gamma_{i}}\right)^{\gamma_{i}}\left(\frac{\lambda_{i}}{\lambda_{i}+\gamma_{i}}\right)
$$

$\eta_{i}$ denotes a count dependent variable assigned as $0,1,2, \ldots, \Gamma(\bullet)$ denotes the gamma function where $\lambda_{i}=\exp \left(x_{i}^{\prime} \beta\right), \gamma_{i}=(1 / a) \lambda_{i}{ }^{k}, \alpha>0$ and is over-dispersed, $k$ is 
set to 1. $E\left(\eta_{i} \mid x_{i}\right)=\lambda_{i}, \operatorname{VAR}\left(\eta_{i} \mid x_{i}\right)=\lambda_{i}+\alpha \lambda_{i}^{2-k}$. Using (8), the probability of having no medical expenditure is $\operatorname{Pr}\left(\eta_{i}=0 \mid x_{i}\right)=\left(\frac{\gamma_{i}}{\lambda_{i}+\gamma_{i}}\right)$, where $\lambda_{i}=\exp \left(x_{i}^{\prime} \beta\right), \gamma_{i}=(1 / a) \lambda_{i}^{k}$. So the probability of using medical services is:

$$
\operatorname{pr}\left(\eta_{i}>0 \mid x_{i}\right)=1-\operatorname{pr}\left(\eta_{i}=0 \mid x_{i}\right)=1-\left(\frac{\gamma_{i}}{\lambda_{i}+\gamma_{i}}\right),
$$

Six regression approaches were analysed for testing part two of TPM. These are OLS, LOLS, GLM with log link and gamma distribution, GLM with power link and gamma distribution, FMM with two classes and FMM with three classes. For GLM with power link and gamma distribution, the appropriate power value being tested in the increments of 0.05 from 0.05 to 1.00 was iteratively determined. The 0.05 power value was found to have the most favourable statistical profile for having the lowest MSE. In Finite Mixture Model (FMM) researcher used a finite mixture of gamma components as $\mathrm{f}($.$) (Deb \& Trivedi, 2002).$

Three criteria were used to compare the six regression approaches in-sample. These include Akaike Information Criterion (AIC), Bayesian Information Criterion (BIC), and Andrew's goodness-of-fit test (GoF) (Deb \& Trivedi, 2002). But in-sample model selection methods were widely criticized for the over-fitting problem. Consequently, the selected model may not be the optimal model. To avoid the potential over-fitting problem, the researcher used a split sample design in each approach's estimation by using $60 \%$ random sample as the calibration sample and remaining $40 \%$ as the validation sample. Firstly, each approach of both Model I and Model II was tested by using calibration sample and then was tested by validation sample as repetition. In comparison of all approaches of two models, variance was avoided by evaluating on the basis of identical split samples.

Two metrics were need to compare the out sample predictive accuracy of the special structure of TPM. Mean Squared Forecast Error (MSFE) and Mean Absolute Prediction Error (MAPE) can be used instead of the standard measures since $R^{2}$ or adjusted $R^{2}$ cannot be used to assess the models (Rajkotia, 2009). The researchers presented the parameter estimation along with observed values of each model in case of total sample as well as each part of sample. Stata 10.0 modelling procedures was used in every analysis.

\section{Results and Discussion}

\subsection{Descriptive analysis}

Figure 1 contains the distribution of medical expenditures of the full enrolled population of Jiaojiang which stood at 330,363 in 2009. The figure leads that medical expenditure distribution in the developing countries is substantially different from those of the developed countries. Data exhibits a substantial mass at zero with a long, thin right tale. Rajkotia (2009) in his study found similar findings and concluded that 
the distribution of health expenditures also exhibits a substantial mass at zero with a long, thin right tale in Ghana.

\section{Figure 1}

\section{Distribution of Medical Expenditures per Person in 2009}

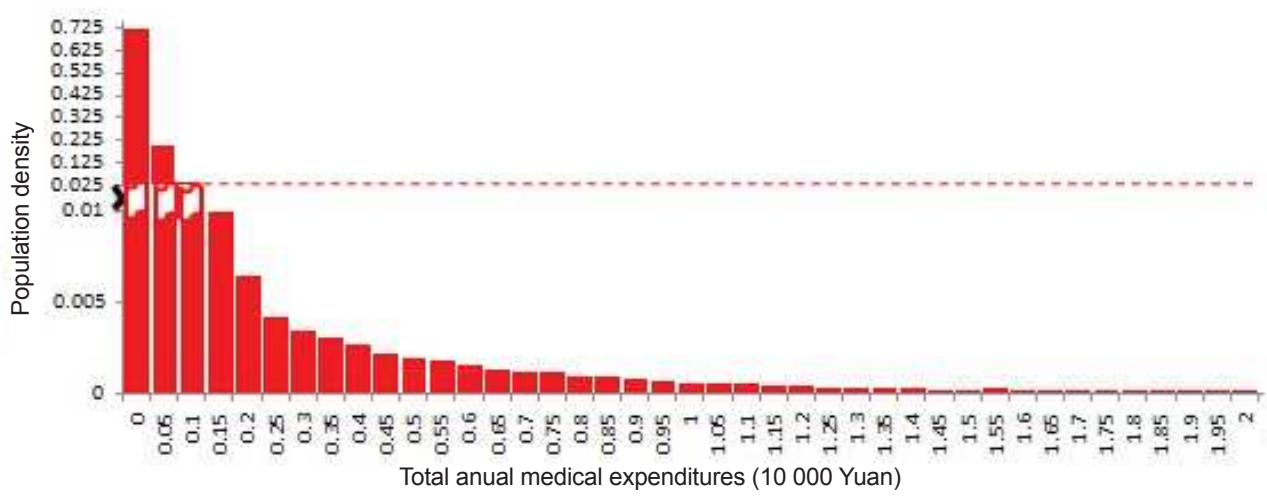

Figure 2 shows the distribution of medical expenditures of the study area by population coverage. More than $50 \%$ of the expenditures were concentrated only within $1 \%$ of the population and $25 \%$ of the population accounted for $99.72 \%$ expenditures. The remaining over $70 \%$ of the respondents was not having with any medical expenditure. Rajkotia (2009) conducted similar study in Ghana and found almost similar findings that more than $50 \%$ of the expenditures of the sample were concentrated among $2 \%$ of the population. Over $50 \%$ of the sample population did not have any medical expenditure during one year.

Figure 2

\section{Concentration of Medical Expenditures}

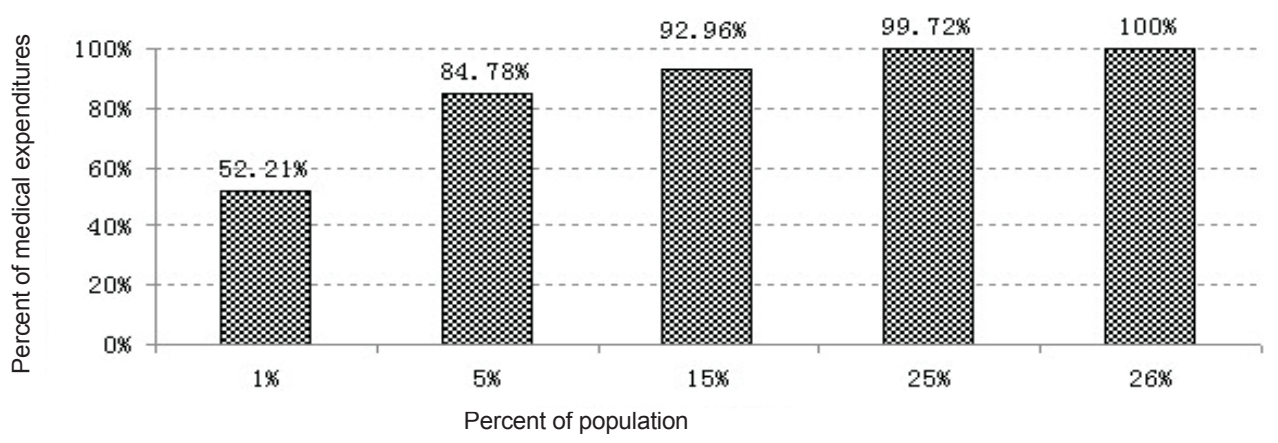


It may be due to the low income level and the great barriers to the formal medical services, which include the opportunity cost of seeking care and geographic distance.Sometimes informal traditional medical services are also more accessible to the peasants. Secondly, the social health insurance systems between the urban and rural areas are distinctly different in China. Huang \& Gan (2010) conducted a study regarding this issue and they found that the medical expenditures of the elderly in urban China were higher than those of the elderly in rural China partly because the security level of the social health insurance to the urban residents was higher than to the peasants. Compared to the social medical insurance in urban area, NRCMS followed a policy of lower benefits, lower contributions and higher co-payments. The cost of medical services is still very high to the majority of the peasants even considering the benefits package of NRCMS and that's why most of the enrolled peasants had zero or almost zero expenditure.

Figure 3 presents mean medical expenditures of male, female and the total sample. The inpatient, outpatient and total medical expenditures of female group were higher than male group. Similar findings were observed in drug expenditures, because drug expenditures were the major part of the total medical expenditures. Zhao (2006) conducted similar study and got also similar findings that the health conditions of the female peasants were worse than the male.

Figure 3

\section{Medical Expenditures per Person by Gender Basis in 2011}

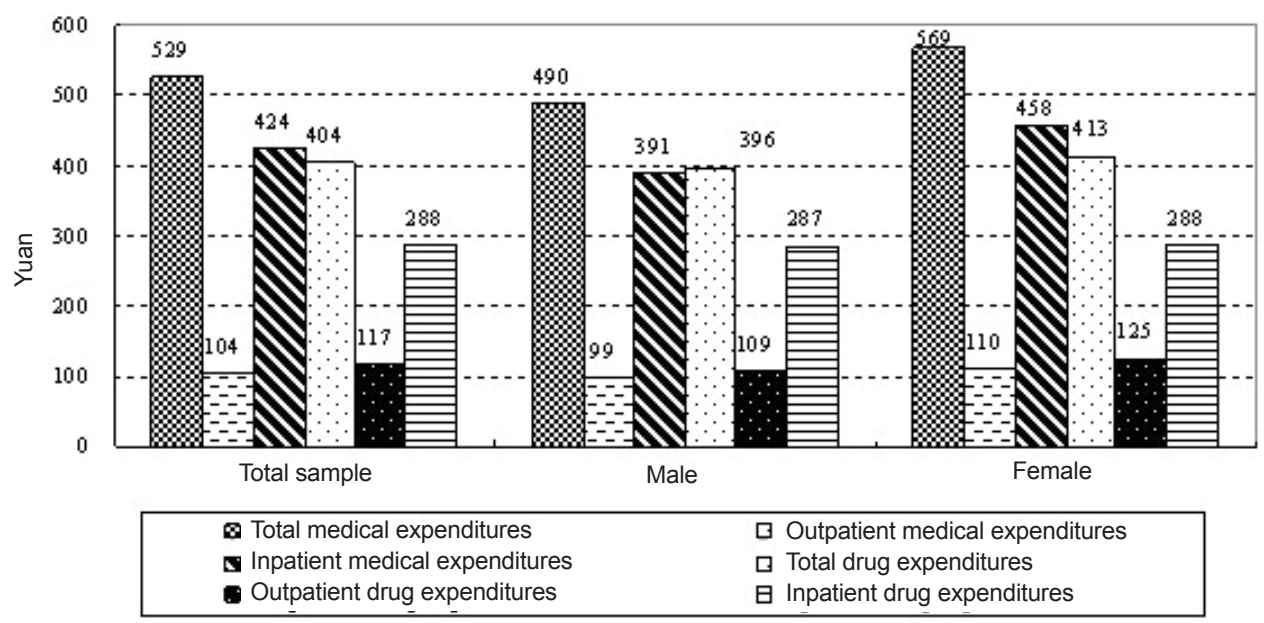

Figure 4 illustrates mean medical expenditures of three different age groups of the respondents (below 18 years, between 18 and 60 years and over 60 years). The enrolled peasants at different age groups had distinct higher medical expenditures. The inpatient, outpatient and total medical expenditures of older age group (over 60 years) were the highest and the younger age group (between 18 and 60 year) had the lowest 
outpatient medical expenditures among the entire beneficiary. In case of below 18 years group, they had lowest inpatient medical expenditures. Zhao (2006) conducted a study and found that the relationship between the age and the health condition of the Chinese peasants was not linear. There was positive relationship between the age and the health condition if the peasants were younger than 30. Oppositely, there was negative relationship between them if the peasants were older than 30 .

Figure 4

\section{Medical Expenditures per Person by Different Age Group in 2011}

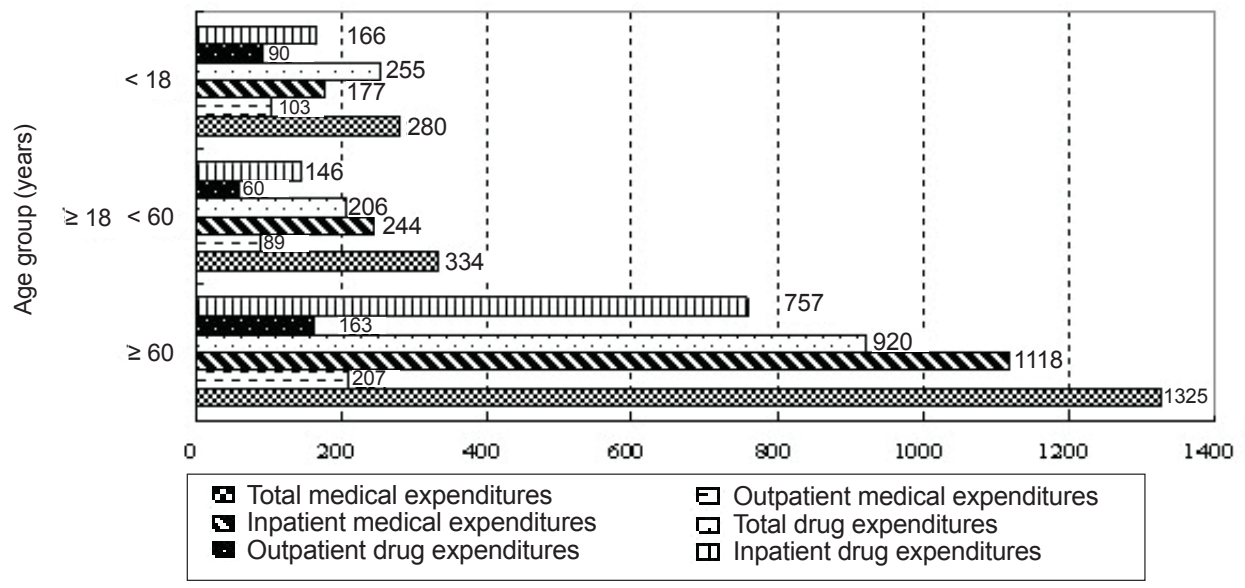

Figure 5 shows the mean frequency of outpatient and inpatient of male, female and total sample of the beneficiary. The mean frequency of outpatient of the total sample was 1.39, which is lower than the female group and higher than the male group. There are little differences in mean inpatient frequency regarding all groups.

Figure 5

Frequency of Oupatient per Person by Gender Basis in 2011

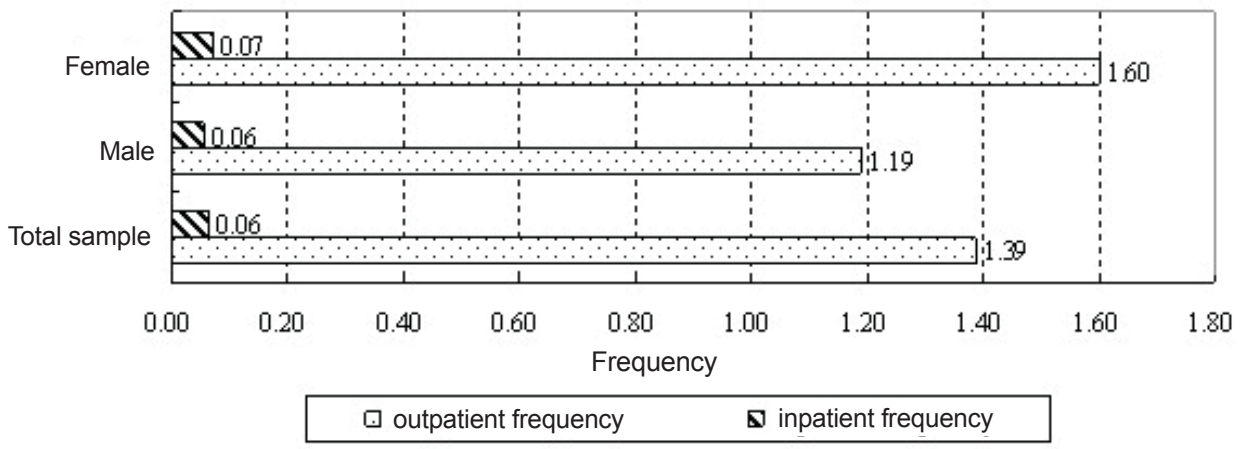


Figure 6 summarizes the mean frequency of outpatient and inpatient of three different age groups of the respondents (below 18 years, between 18 and 60 years and over 60 years). The mean frequency of both outpatient and inpatient of old age group (over 60 years) were the highest among all age groups. Oppositely, younger age group (between 18 and 60 year) had the lowest mean frequency of outpatient and inpatient.

Figure 6

Frequency of Outpatient and Inpatient per Person by Age Group in 2011

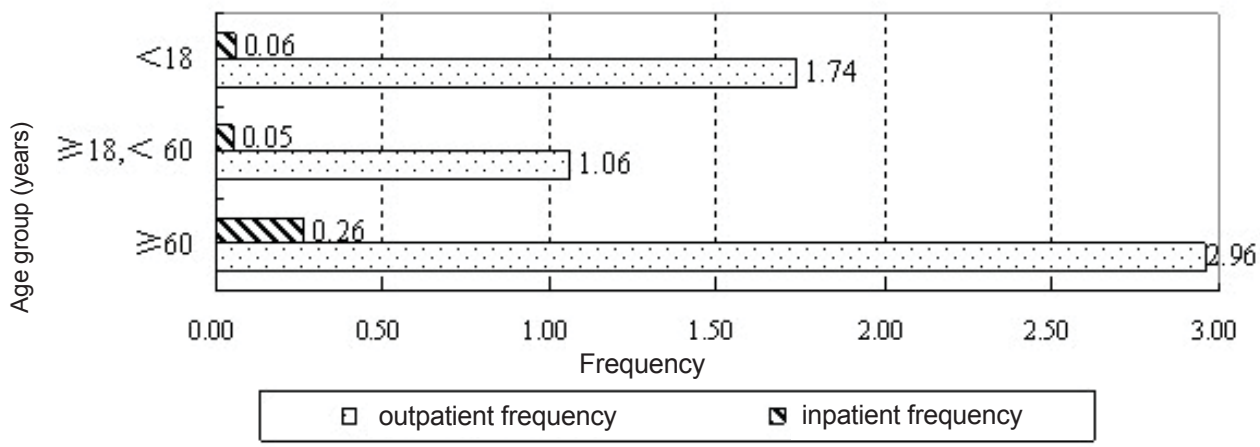

\subsection{Econometric results}

Table 3

The Predictive Accuracy of Alternate Approaches of Model 1 and Model 2

\begin{tabular}{|c|c|r|r|r|r|r|r|}
\hline \multicolumn{2}{|c|}{} & \multicolumn{6}{|c|}{ Approach } \\
\cline { 3 - 8 } \multicolumn{2}{c|}{} & OLS & LOLS & $\begin{array}{c}\text { GLM } \\
\text { (log link) }\end{array}$ & $\begin{array}{c}\text { GLM } \\
\text { (power link) }\end{array}$ & FMM2 & FMM3 \\
\hline \multirow{2}{*}{ AIC } & Model 1 & 160544 & 99896 & 93635 & 93693 & 95144 & 94889 \\
\cline { 2 - 8 } & Model 2 & 159002 & 99326 & 93111 & 93226 & 94975 & 94585 \\
\hline \multirow{2}{*}{ BIC } & Model 1 & 160596 & 99948 & 93687 & 93745 & 95208 & 94953 \\
\cline { 2 - 8 } & Model 2 & 159054 & 99378 & 93163 & 93278 & 95039 & 94649 \\
\hline \multirow{2}{*}{ GoF } & Model 1 & 931 & 706 & 539 & 546 & 601 & 587 \\
\cline { 2 - 8 } & Model 2 & 825 & 482 & 462 & 499 & 590 & 568 \\
\hline \multirow{2}{*}{ MSFE } & Model 1 & 0.0180924 & 0.0149970 & 0.0145271 & 0.0145003 & 0.0147102 & 0.0147054 \\
\cline { 2 - 8 } & Model 2 & 0.0179023 & 0.0140784 & 0.0138782 & 0.0138917 & 0.0142196 & 0.0143586 \\
\hline \multirow{2}{*}{ MAPE } & Model 1 & 0.0002048 & 0.0002533 & 0.0003079 & 0.0002997 & 0.0002746 & 0.0002702 \\
\cline { 2 - 8 } & Model 2 & 0.0002196 & 0.0002932 & 0.0003266 & 0.0003201 & 0.0003008 & 0.0002897 \\
\hline
\end{tabular}

Table 3 presents both the in-sample and the out-of-sample predictive accuracy of each modelling approach of Model I and Model II. For Model I, GLM(log link) was the best performer and OLS was the worst one based on the AIC, BIC and GoF criteria. GLM(power link) was the best performer and OLS was the worst based on the MSFE 
statistics. GLM(log link) was the best performer and LOLS was the worst based on the MAPE statistics. But for Model II, GLM(log link) was the best performer and OLS was the worst based on the AIC, BIC, GoF, MSFE and MAPE statistics. And both the in-sample and the out-of-sample predictive accuracy of each modelling approach of Model II are better than Model I based on the AIC, BIC, GoF, MSFE and MAPE statistics. The finding reveals that the predictive accuracy of each modelling approach could be improved by adding QWB as a new explanatory variable. So the further parameter estimation was made of Model II.

Table 4

Total Annual Expenditures: Parameter Estimates from Six Approaches for Model 2

\begin{tabular}{|c|c|c|c|c|c|c|c|c|c|}
\hline \multirow{3}{*}{ Variable } & \multicolumn{9}{|c|}{ Approach } \\
\hline & \multirow{2}{*}{ OLS } & \multirow{2}{*}{ LOLS } & \multirow{2}{*}{$\begin{array}{c}\text { GLM } \\
\text { (log link) }\end{array}$} & \multirow{2}{*}{$\begin{array}{c}\text { GLM } \\
\text { (power link) }\end{array}$} & \multicolumn{2}{|c|}{ FMM2 } & \multicolumn{3}{|c|}{ FMM3 } \\
\hline & & & & & COMP 1 & COMP 2 & COMP 1 & COMP 2 & COMP 3 \\
\hline Age & $\begin{array}{c}0.186^{* * *} \\
(0.01)\end{array}$ & $\begin{array}{c}0.023^{* * *} \\
(0.00)\end{array}$ & $(0.00)$ & $\begin{array}{c}0.012^{* * *} \\
(0.00)\end{array}$ & & & $\begin{array}{c}0.009^{* * *} \\
(0.00)\end{array}$ & & \\
\hline Size & & & & & & & & & \\
\hline Gender & $\begin{array}{c}-1.970^{* * *} \\
(0.41)\end{array}$ & $\begin{array}{c}-0.683^{* *} \\
(0.03)\end{array}$ & \begin{tabular}{|c|}
$-0.398^{* * *}$ \\
$(0.00)$
\end{tabular} & $\begin{array}{c}-0.406^{* * *} \\
(0.00)\end{array}$ & $\begin{array}{c}-0.581^{* *} \\
(0.02)\end{array}$ & $\begin{array}{c}-0.607^{* *} \\
(0.03)\end{array}$ & $\begin{array}{l}0.097^{* *} \\
(0.00)\end{array}$ & & \\
\hline Zone I & $\begin{array}{c}-0.381^{* * *} \\
(0.18)\end{array}$ & $\begin{array}{c}-0.147^{* *} \\
(0.02)\end{array}$ & $\begin{array}{c}-0.098^{* * *} \\
(0.00)\end{array}$ & $\begin{array}{c}-0.083^{* * *} \\
(0.00)\end{array}$ & $\begin{array}{c}-0.162^{\star * *} \\
(0.03)\end{array}$ & $\begin{array}{c}-0.201^{\text {*** }} \\
(0.05)\end{array}$ & $\begin{array}{c}-0.077^{* * *} \\
(0.02)\end{array}$ & $\begin{array}{c}-0.253^{* * *} \\
(0.02)\end{array}$ & $\begin{array}{c}-0.325^{\star * *} \\
(0.00)\end{array}$ \\
\hline zone & $\begin{array}{c}0.293^{* * *} \\
(0.09)\end{array}$ & $\begin{array}{c}0.024^{* *} \\
(0.00)\end{array}$ & $\begin{array}{c}0.210^{* * *} \\
(0.00)\end{array}$ & $\begin{array}{c}0.042^{* * *} \\
(0.00)\end{array}$ & $\begin{array}{c}0.035^{\star *} \\
(0.00)\end{array}$ & $\begin{array}{c}0.118^{* *} \\
(0.00)\end{array}$ & & $\begin{array}{c}0.032^{* *} \\
(0.00)\end{array}$ & $\begin{array}{c}0.089^{* * \star} \\
(0.00)\end{array}$ \\
\hline Zone III & $\begin{array}{c}0.046^{* \star *} \\
(0.20)\end{array}$ & $\begin{array}{c}0.032^{* * *} \\
(0.01)\end{array}$ & $\begin{array}{c}0.016^{* * *} \\
(0.00)\end{array}$ & $\begin{array}{c}0.017^{* * *} \\
(0.00)\end{array}$ & $\begin{array}{c}0.011^{* *} \\
(0.00)\end{array}$ & $\begin{array}{c}0.023^{* *} \\
(0.00)\end{array}$ & $\begin{array}{c}0.006^{\star * \star} \\
(0.00)\end{array}$ & $\begin{array}{c}0.041^{\star * \star} \\
(0.00)\end{array}$ & $\begin{array}{c}0.029^{* *} \\
(0.00)\end{array}$ \\
\hline QWB & $\begin{array}{c}-13.698^{* * *} \\
(0.07)\end{array}$ & $\begin{array}{c}-0.781^{* * \star} \\
(0.01)\end{array}$ & $\begin{array}{c}-0.061^{* * *} \\
(0.00)\end{array}$ & $\begin{array}{c}-0.058^{* * *} \\
(0.00)\end{array}$ & $\begin{array}{c}0.091^{* *} \\
(0.00)\end{array}$ & $\begin{array}{c}0.018^{* *} \\
(0.00)\end{array}$ & $\begin{array}{c}0.023^{* * *} \\
(0.00)\end{array}$ & $\begin{array}{c}0.030^{* * *} \\
(0.00)\end{array}$ & $\begin{array}{c}0.0061^{* *} \\
(0.00)\end{array}$ \\
\hline
\end{tabular}

${ }^{*} \mathrm{p}<.1,{ }^{* *} \mathrm{p}<.05,{ }^{* * *} \mathrm{p}<.01$

Table 4 shows the parameter estimation of six alternative approaches of Model 2. Several variables were significantly associated with the patient's medical expenditures at $p<0.01$ such as age, gender, zone (I, II and III) from GLM (log link). The direction of coefficients of different zone variables is not consistent. This shows the influence of the level of urbanization and economic development of different zone where the enrolled peasants lived on complicated medical expenditures. Peasants may increase medical services expenses with the improvement of their standard of living and the change of the ideas of care seeking. But peasants may decrease the spending on medical services since physical conditions have greatly improved after complete urbanization. Different findings observed by Grossman (1972), Zhao (2006) and Lin \& Shu (2007). Grossman (1972) found that higher income group would produce health capital more effectively and needed less health care. Zhao (2006) found that the health condition of the peasant who lived in the suburban areas of a city had been worsening within the progress of urbanization. And they had to pay for some medical services at the same or even higher 
price as the urban residents with the higher income level. Lin \& Shu (2007) offered an empirical study of factors determining the medical expenditures of Chinese people and found that income played significant roles in determining the use of medical care facilities. Based on change of age, gender structure and the spatial distribution of the enrolled peasants, the policy makers may monitor the change of NRCMS expenses for getting financial sustainability. Based on predictive accuracy, GLM (log link) should be the best approach for the total sample and also for each sub-group (Table 5). The predictive accuracy is not good against FMM. For instance, FMM2 was the worst performer in the female sub-group.

Table 5

Prediction of Medical Expenditures by Six Approaches

\begin{tabular}{|l|c|c|c|c|c|c|}
\hline Approach & $\begin{array}{c}\text { Total sample } \\
\text { (mean= } \\
\mathbf{5 2 8 . 5 7})\end{array}$ & $\begin{array}{c}\text { Male } \\
\text { (mean= } \\
\mathbf{4 9 0 . 2 5 )}\end{array}$ & $\begin{array}{c}\text { Female } \\
\text { (mean= }\end{array}$ & $\begin{array}{c}\text { Below 18 } \\
\text { years } \\
\text { (mean= } \\
\mathbf{2 8 0 . 4 2})\end{array}$ & $\begin{array}{c}\text { Between 18 } \\
\text { and 60 years } \\
\text { (mean= } \\
\mathbf{3 3 3 . 7 4 )}\end{array}$ & $\begin{array}{c}\text { Over 60 years } \\
\text { (mean= } \\
\mathbf{1 3 2 5 . 0 1 )}\end{array}$ \\
\hline OLS & 439.07 & 583.18 & 679.29 & 347.95 & 394.82 & 1502.49 \\
\hline LOLS & 477.65 & 554.74 & 630.47 & 324.12 & 376.33 & 1473.28 \\
\hline GLM(log) & 547.48 & 498.96 & 592.35 & 265.97 & 327.16 & 1375.35 \\
\hline GLM(power) & 552.91 & 503.73 & 604.81 & 257.46 & 320.58 & 1380.36 \\
\hline FMM2 & 469.35 & 429.01 & 457.64 & 239.58 & 389.45 & 1427.68 \\
\hline FMM3 & 477.27 & 437.85 & 562.86 & 246.73 & 382.59 & 1416.37 \\
\hline
\end{tabular}

FMM is stratifying beneficiaries by the intensity of medical expenditures, but all of the approaches comparison based on parameter estimation (Table 4) and predictive accuracy (Table 3 and Table 5) show that FMM may not offer a more accurate prediction and additional information than the other modelling approaches. Rajkotia (2009) conducted similar study and found also similar findings that FMM did not perform better than other modelling approaches for predictive accuracy and in many cases, performed worse.

\section{Conclusions and Implications}

The ultimate goal is to provide medical support service to the rural people through NRCMS and it is an important task for the Chinese government. A reliable model could not only yield forecast of enrolled peasant's medical expenditures, but also carry reliable information to take decision for financing medical services. These two mentioned issues have major policy implications. This research presents the comparison of the predictive accuracy of the six most common econometric approaches for modelling the medical expenditures by using NRCMS data. 
This study found that by adding QWB as a new explanatory variable, the out-ofsample predictive accuracy of each modelling approach could be improved based on the MAPE, MSFE and BIC statistics. So under NRCMS, the concerned authority may consider storing the information about the health conditions of the enrolled respondents along with the basic demographic information.

And the findings based on the MAPE, MSFE and BIC statistics reveals that the performances of GLM(log link) is relatively better than the other approaches. But in case of the developed countries, contrary findings were found. The performance of FMM in China is not as good as expectation, but it is popular in developed countries. It may be due to the significant difference of the distribution of medical expenditures between China (developing country) and those of the developed countries. The medical expenditures in the developed countries usually exhibit the distribution with a long, thick right tale and a substantial mass at zero. But the sample of this study exhibits a long, thin right tale.

All approaches include GLM assuming the medical expenditures of individual are independent from each other. The utilization of medical services may act or react on each other among the family members. This may serve as the basis for further improvements of GLM application for prediction of medical expenditures.

The findings of the research may serve as a guideline for Chinese government personnel who are dealing with medical support service program. However, the findings may also have implications to other developing countries where the physical, socioeconomic, cultural and geographical conditions are almost similar to the research area. The findings are expected to help the academicians, professional, government policymakers, researchers, trainers, development practitioners, and other personnel who are directly or indirectly connected with medical support service program to bring in more sophistication in this sector and then play an important role for rural development as well as national economic development.

\section{References}

Becker, G. S. (1964), Human Capital. Chicago, Illinois: University of Chicago Press.

Blough, D. K., Madden, C. W., Hornbrook, M. C. (1999), "Modeling Risk Using Generalized Linear Models." Journal of Health Economics, Vol. 18, No. 2, pp. 153-171.

Buntin, M. B., Zaslavsky, A. M. (2004), "Too Much Ado about Two-part Models and Transformation? Comparing Methods of Modeling Medicare Expenditures." Journal of Health Economics, Vol. 23, No. 3, pp. 525-542.

Deb, P., Trivedi, P. K. (2002), "The Structure of Demand for Health Care: Latent Class versus Two-part Models." Journal of Health Economics, Vol. 21, No. 4, pp. 601-625.

Duan, N. (1983), "Smearing Estimate: A Nonparametric Retransformation Method." Journal of the American Statistical Association, Vol. 78, No. 383, pp. 605-610.

Fen, J., Qin, B. (2006), "Consumption of Medical Care in Rural China." World Economic Papers, No. 1, pp. 75-88. 
Gerdtham, U., Trivedi, P. K. (2001), "Equity in Swedish Health Care Reconsidered: New Results Based on the Finite Mixture Model." Journal of Health Economics, Vol. 10, No. 6.

Grossman, M. (1972), The Demand for Health: A Theoretical and Empirical Investigation. New York: Columbia University Press for NBER.

Huang, F., Gan, L. (2010), “Excess Demand or Appropriate Demand? Health Insurance, Medical Care and Mortality of the Elderly in Urban China." Economic Research Journal, No. 6, pp. 105-119.

Hay, J. W., Olsen, R. J. (1984), "Let Them Eat Cake: A Note on Comparing Alternative Models of the Demand for Medical Care." Journal of Business \& Economic Statistics, Vol. 2, No. 3, pp. 279-282.

Kaplan, R., Anderson, J. P. (1988), "A General Health Policy Model: Update and Applications." Health Services Research, Vol. 23, No. 2, pp. 203-235.

Kenkel, D. (1990), "Consumer Health Information and the Demand for Medical Care." The Review of Economics and Statistics, Vol. 72, No. 4, pp. 587-595.

Klugman, S. A., Panjer, H. H., Willmot, G. E. (2008), Loss Models: From Data to Decisions. 3rd edition. New Jersey: John Wiley \& Sons.

Lin, X., Shu, Y. (2007), "Determinants of the Chinese Residents' Medical Expenditures." South China Journal of Economics, No. 6, pp. 22-30.

McCullagh, P., Nelder, J. A. (1989), Generalized Linear Models. 2nd edition. London: Chapman and Hall.

Mocan, H., Tekin, N., Jeffrey, E., Zax, S. (2004), "The Demand for Medical Care in Urban China." World Development, Vol. 32, No. 2, pp. 289-304.

Ministry of Health of the People's Republic of China. National Statistical Communique on the Development of Health Service, 2004-2009. Available at http://www.moh.gov.cn/publicfiles/ business/htmlfiles/zwgkzt/pgb/index.htm.

Rajkotia, Y. (2009), "National Health Insurance in Ghana: Politics, Adverse Selection, and the Use of Child Health Services." Dissertation at the Johns Hopkins University. Available at http://gradworks. umi.com/33/57/3357175.html.

Rein, D. B. (2005), "A Matter of Classes: Stratifying Health Care Populations to Produce Better Estimates of Inpatient Costs." Health Services Research, Vol. 40, No. 4, pp. 1217-1233.

Sosa-Rubi, S. G. (2004), "Modeling Maternal Health Care Utilization in Mexico: Latent Class Analysis for Modeling Unobserved Heterogeneity in the Population." Applied Health Economics and Health Policy, Vol. 3, No. 1 (supplement), p. 64.

Xie, E. (2009), "Income-related Inequality of Health and Health Care Utilization." Economic Research Journal, No. 2, pp. 92-105.

Zhao, Z. (2006), "Health Condition and Influence Factors of China's Rural Population." Management World, No. 3, pp. 78-85. 